Medicine Takers, Prescribers, and Hoarders ${ }^{10}$

Eighty-five per cent of the adults whose doctor completed the questionnaire thought that their doctor had enough time to listen and do everything necessary for patients; fewer of those with doctors who did not reply $(76 \%)$ described their general practitioner in those terms. A possible explanation is that the doctors who did not collaborate were busier than the others, so one reason for noncollaboration was lack of time. Adults were also asked whether they would discuss a personal problem with their doctor. Forty-four per cent of those whose doctor replied said they would, compared with $37 \%$ of the others. Nevertheless, the patients of those doctors who did not collaborate had consulted their doctors a similar number of times during the previous year to those people whose doctors completed the questionnaire. More importantly for the study, the proportions of people who had taken medicine, either prescribed or non-prescribed, did not differ.

\section{Life Before Death ${ }^{5}$}

There was no difference in the place of death of patients whose doctors participated in the study and those who did not, but patients of doctors who did not collaborate were less likely to have had 10 or more home visits in the year before they died (35\% compared with $44 \%$ of patients whose doctors did take part) and they were less likely to have been visited by a district nurse (27\% compared with $39 \%)$. Relatives more often thought that the doctor did not have time to discuss things when he failed to reply to the questionnaire $(24 \%$ compared with $14 \%$ ). A higher proportion said that they had known what was wrong with their dead relative when the doctor co-operated $(51 \%)$ than when he did not $(38 \%)$, and more of them said that they had got most of their information from their dead relative's general practitioner ( $48 \%$ compared with $37 \%$ ). These findings suggest that the general practitioners who responded may have had a somewhat closer relationship with their patients and their patients' families than those who did not.

\section{Patients and Their Doctors in $1977^{\circ}$}

Unlike the study of medicines, patients' assessments of doctors who did and did not respond did not differ about their listening or taking time. Nor did the two groups differ in their assessments of whether they would discuss a personal problem with their doctor. The two groups seemed to be equally satisfied or dissatisfied with their care and equally critical or uncritical of their doctors. If the patients saw their relationship with their doctor as businesslike, the doctor was more likely to respond than if the patient described it as friendly (70\% compared with $60 \%$ ). Perhaps the businesslike doctors are more systematic.

\section{Discussion}

On the whole the comparisons between the professionals who participated in our studies and those who did not are reassuring because they do not indicate any large bias. The same conclusion was reached in an American study of physicians who did and did not respond to a postal questionnaire, ${ }^{12}$ even though the response rates in our studies sometimes dropped to a level that they would regard as unacceptably low. In practice the extent of the biases did not seem to be strongly related to the response rate: the number and direction of identified biases was at least as great in the study of terminal care, in which the response rate was $79 \%$, as in the study of medicines, in which it was $56 \%$.

Probably the most worrying finding is the drop in response from doctors over time. One possible explanation may be an increasing apathy or antagonism towards health-service research associated with government. This would be ironic, since the aim of much research is to ensure that bureaucrats are aware of the views of the people concerned. Alternatively, doctors may have become the targets for an increasing number of studies, and some may have responded by rejecting all such appeals, others by responding selectively to those that they find particularly interesting, and others by demanding the type of reward that is sometimes offered by pharmaceutical firms when they do such studies. Some evidence suggested that certain subjects were seen as more threatening than others, and also that some topics appealed to certain types of doctors. Health visitors, midwives, and district nurses, on the otherhand, seem to be asked about their professional views and experiences relatively infrequently. Several of them said that they were glad that we were taking notice of their point of view, and this feeling, together with their inclination to accept what their seniors had approved, probably contributed to their relatively high rate of response.

The direction of the biases that were identified among the non-responding doctors suggested that they were older, more isolated, less well-qualified, and rather less likely to be regarded as helpful and sympathetic by their patients. They also seemed to have a less positive attitude to research.

I thank Abe Adelstein, Robert Anderson, Valerie Beral, Charlie Cannell, Karen Dunnell, Wendy Farrant, Rosalind Lam, Jean Martin, Louis Moss, Alison Venning, Marjorie Waite, and Audrey Ward for helpful comments.

\section{References}

1 Cartwright, A, The Dignity of Labour? In press.

2 Cartwright, A, Medical Officer, 1968, 120, 43.

3 Cartwright, A, Studies in Family Planning, 1968, 32, 10.

4 Cartwright, A, Parents and Family Planning Services. London, Routledge and Kegan Paul, 1970

5 Cartwright, A, Hockey, L, and Anderson, J L, Life before Death. London, Routledge and Kegan Paul, 1973.

${ }^{6}$ Cartwright, A, and Ward, A, British Fournal of Preventive and Social Medicine, 1968, 22, 199.

${ }^{7}$ Cartwright, A, Patients and Their Doctors. London, Routledge and Kegan Paul, 1967.

${ }^{8}$ Cartwright, A, and Anderson, R, Patients and Their Doctors in 1977. Evidence to the Royal Commission on the National Health Service, 1978.

${ }^{9}$ Cartwright, A, and Waite, M, Fournal of the Royal College of General Practitioners, 1972, suppl No 2, p 22.

${ }^{10}$ Dunnell, K, and Cartwright, A, Medicine. Takers, Prescribers and Hoarders. London, Routledge and Kegan Paul, 1972.

11 Waite, M, Consultant Gynaecologists and Birth Control. London, The Birth Control Trust, 1974.

12 Gough, H G, and Hall, W B, fournal of Applied Psychology, 1977, 62, 777.

13 Cartwright, A, Human Relations and Hospital Care. London, Routledge and Kegan Paul, 1964.

14 Cartwright, A, and Marshall, R, Medical Care, 1965, 3, 69.

15 Waite, M, Nursing Times, 12 October 1972.

16 Waite, M, Nursing Times, 14 December 1972.

17 Waite, M, British Medical fournal, 1973, 2, 629

18 Waite, M, Journal of Psychological Medicine, 1974, 4, 74

(Accepted 18 August 1978)

\section{What is the nature of the blood-brain barrier?}

It has been known for many years that there are substances that penetrate into the central nervous system either very slowly, or not at all, but which readily enter other tissues. The exact site of this bloodbrain barrier is still debated, but is probably due to the tight junctions between endothelial cells of brain capillaries. The passage of substances across the blood-brain barrier is largely determined by their facility to cross (and therefore dissolve in) the lipid membranes of the surrounding endothelial cells. Lipid-soluble drugs therefore penetrate into the central nervous system very readily, while most lipid insoluble ones do not. Few substances (such as levodopa), however, cross by active transport. In meningitis, encephalitis, and uraemia there is some degree of "breakdown" of the blood-brain barrier, which allows penicillin to cross into the central nervous system.

\section{Correction}

\section{Brucellosis}

In the Any Question? on brucellae and Mycobacterium tuberculosis (4 November, $\mathrm{p} 1281$ ) the co-trimoxazole dosage should have been given as 10 and $50 \mathrm{mg} / \mathrm{kg}$ daily. 